\title{
Transformation Analysis of Carbon and Nitrogen Compounds in Wastewater Treated in a Vertical Biofilter
}

\author{
Dariusz Wawrentowicz ${ }^{1}$ \\ 1 Department of Water Supply and Sewage Systems, Bialystok University of Technology, ul. Wiejska 45E, \\ 15-351 Białystok, Poland \\ e-mail: d.wawrentowicz@pb.edu.pl
}

\begin{abstract}
Biofilter technology for wastewater treatment is relatively complex and is gaining more interest. However, it should be emphasised that various aerobic conditions may occur in biological filter beds, which depend primarily on the velocity of wastewater flow through the bed. Therefore, it is often difficult to precisely determine the transformations of carbon and nitrogen compounds that occur during wastewater treatment on these types of filter beds. This study investigated the effectiveness of the filter bed and analysed the extent of the transformation of carbon and nitrogen compounds in the range of filtration velocities from 0.02 to $0.60 \mathrm{~m} \cdot \mathrm{h}^{-1}$. The study was conducted under laboratory conditions, and model wastewater was prepared on the basis of sodium acetate, ammonium chloride, potassium nitrate and potassium dihydrogen phosphate. The model wastewater was prepared with parameters corresponding to those of the treated wastewater. The experiment showed that anaerobic and aerobic conditions occurred in the biological filter bed at filtration velocities of up to $0.16 \mathrm{~m} \cdot \mathrm{h}^{-1}$. Above this velocity, aerobic conditions prevailed in the biological filter bed.
\end{abstract}

Keywords: COD removal, nitrogen forms, biofilter

\section{INTRODUCTION}

Biological wastewater treatment systems are one of the most common wastewater treatment methods in the world [Andreottola et al. 2009, Song et al. 2014]. Properly adjusted technological conditions make it possible to achieve satisfactory removal of carbon, nitrogen and phosphorus compounds [Turkmenler and Aslan 2017, Ofman and Struk-Sokołowska, 2019, Joshiba et al. 2019]. However, it should be emphasised that biological processes cannot completely remove the pollutants flowing into the treatment plant in the raw wastewater stream [Gizgis et al. 2006]. Therefore, treated wastewater mainly contains hardly biodegradable carbon compounds expressed as COD and residual amounts of nitrogen compounds [Ma et al. 2020, Liang et al. 2007]. It is important to note here that Polish legislation does not require the specification of nitrogen forms in treated wastewater and only the total nitrogen form in the treated wastewater is standardised. Nevertheless, treated wastewater most often contains nitrogen in the form of ammonium and nitrate (V). These forms are classified as biogenic compounds which may cause secondary pollution of the receiving water body due to deterioration of its aerobic conditions [Struk-Sokołowska et al. 2020]. This phenomenon is connected with increased uptake of oxygen in receiver waters as a result of the oxidation processes of pollutants present in them [Skorbiłowicz and Ofman 2014, Kanaujiya et al. 2019, Veetil et al. 2021].

A potential solution to the indicated problem could be the use of biological filters as a third stage of wastewater treatment [Wang et al. 2008, Hassan et al. 2021]. This technology is based on the use of porous material as a carrier to immobilise microorganisms [Yang et al. 2021]. This leads to the growth of microorganism consortia in a controlled volume, resulting in conditions allowing for the intensification of carbon and nitrogen 
transformations [Wang, 2021]. It should be emphasised that achieving satisfactory efficiency of carbon and nitrogen removal from treated wastewater in additional stages of wastewater treatment is fraught with certain difficulties, which arise from the biochemical aspect [Dong et al. 2019]. The COD values observed in the treated wastewater correspond mainly to carbon compounds that are difficult to biodegrade and have not been removed by biodegradation and biosorption during the biological treatment stage. The removal of nitrogen compounds, on the other hand, requires both an adequate amount of biodegradable carbon for the denitrification process and an adequate alkalinity and dissolved oxygen concentration for the oxidation of ammonium nitrogen in the case of nitrification [Nasir et al. 2019, Rahimi et al. 2020].

Taking into account the described issue of carbon and nitrogen removal from treated wastewater, this paper analyses the processes of carbon removal expressed as COD, denitrification and nitrification in a biofilter bed. The aim of the study was to identify the technological conditions that would allow the most effective removal of these pollutants from model treated wastewater.

\section{MATERIALS AND METHODS}

The research was conducted under laboratory conditions in a model biological filter. The filter was filled with filter grit of different granulation. The total height of the filter bed was $200 \mathrm{~mm}$ and its internal diameter was $50 \mathrm{~mm}$. The filter layer on which the biological film was grown accounted for $50 \%$ of the total bed filling and consisted of grit with a diameter of 2 to $3 \mathrm{~mm}$. Above the biological layer a grit layer of the same granulation was used to retain suspended solids. This layer accounted for $20 \%$ of the total height and was periodically cleaned of suspended solids in order to maintain the hydraulic conditions of flow through the bed. The final element of the filter filling was two holding layers, which consisted of grit with a granulation of 3 to $5 \mathrm{~mm}$ and grit with a granulation of 5 to $8 \mathrm{~mm}$. The height of the first holding layer was equal to $20 \%$ of the total height of the filter bed, while the second layer accounted for $10 \%$ of the total filter bed height. The biological layer of the filter bed was made on the basis of an activated sludge inoculum with a volume of $200 \mathrm{~mL}$, which contained $1 \mathrm{~g}$ of dry matter. This volume of activated sludge was applied to the layer intended for the biological part and adjusted to laboratory conditions for a period of 60 days.

The experiments were carried out with the volume of the wastewater stream flowing through the filter bed ranging from 1 to $40 \mathrm{~mL} \cdot \mathrm{min}^{-1}$. Each of the flows was maintained in the bed for 3 days. It should be stressed out that this period was necessary for the microorganisms to adapt to the new operating conditions of the filter bed. Along with an increase in the wastewater volume, the unit quantity of nutrients flowing into the biological part also increased. This required the microorganisms to adapt to the production of more enzymes allowing the biodegradation of carbon and nitrogen compounds in the wastewater flowing into the bed. Table 1 presents selected technological parameters of the filter bed, which were maintained during the experiment.

The filter bed was fed with model wastewater prepared from sodium acetate $\left(103.00 \pm 0.51 \mathrm{mg} \cdot \mathrm{L}^{-1}\right)$, ammonium chloride $\left(6.79 \pm 0.14 \mathrm{mg} \cdot \mathrm{L}^{-1}\right)$, potassium nitrate $\left(2.74 \pm 0.08 \mathrm{mg} \cdot \mathrm{L}^{-1}\right)$ and potassium dihydrogen phosphate $\left(2.52 \pm 0.11 \mathrm{mg} \cdot \mathrm{L}^{-1}\right)$. The model wastewater was prepared to reflect the parameters of the wastewater treated at the biological stage. The mixture of substances used allowed to obtain appropriate concentrations of carbon compounds, nitrogen and phosphorus in the wastewater [Ofman and Struk-Sokołowska, 2019]. The individual substances were dissolved in dechlorinated tap water. This approach made it possible to limit the oxidising character of free chlorine present in the tap water. The parameters of the model wastewater flowing into the filter bed were presented in Table 2.

Laboratory analyses including measurement of COD, N-NH $\mathrm{N}_{4}, \mathrm{~N}-\mathrm{NO}_{2}$ and $\mathrm{N}-\mathrm{NO}_{3}$ were performed by spectrophotometric method using a Merck UV-VIS Pharo 300 spectrophotometer. The reagents recommended by the manufacturer were used for the determinations, and the analytical procedure was carried out according to the instructions supplied with the reagents manufacturer. The $\mathrm{pH}$ and dissolved oxygen were measured using a multi-parameter probe YSI Professional by WTW.

The research was summarised by an analysis of Pearson's correlation coefficients, aimed at verifying which of the biofilter technological parameters or raw sewage flowing into the filter bed had the greatest effect on the course of transformations of carbon and nitrogen compounds. 
Table 1. Technological parameters of the filter bed

\begin{tabular}{|l|c|c|}
\hline \multicolumn{1}{|c|}{ Technological parameter } & Unit & Range \\
\hline Volumetric flow rate $(\mathrm{Q})$ & $\mathrm{mL} \cdot \mathrm{min}^{-1}$ & $1.0-40.0$ \\
\hline Linear flow velocity through the filter bed $\left(\mathrm{V}_{\mathrm{F}}\right)$ & $\mathrm{m} \cdot \mathrm{h}^{-1}$ & $0.02-0.60$ \\
\hline Contact time between wastewater and filter bed $\left(\mathrm{T}_{\mathrm{F}}\right)$ & $\mathrm{min}$ & $19.0-769.0$ \\
\hline Contact time of wastewater with biological layer $\left(\mathrm{T}_{\mathrm{B}}\right)$ & $\mathrm{min}$ & $10.0-385.0$ \\
\hline Hydraulic load on the filter bed $\left(H \mathrm{HL} \mathrm{R}_{\mathrm{F}}\right)$ & $\mathrm{L} \cdot \mathrm{m}^{-2} \cdot \mathrm{d}^{-1}$ & $0.02-0.62$ \\
\hline
\end{tabular}

Table 2. Parameters of wastewater flowing into the filter bed

\begin{tabular}{|c|c|c|c|c|c|}
\hline Parameter & Unit & Arithmetic mean & Standard deviation & Minimum & Maximum \\
\hline $\mathrm{pH}$ & - & - & - & 7.59 & 7.67 \\
\hline $\mathrm{O}_{2}$ & \multirow{5}{*}{$\mathrm{mg} \cdot \mathrm{L}^{-1}$} & 6.16 & 0.06 & 6.06 & 6.30 \\
\hline COD & & 111.37 & 1.42 & 108.00 & 115.00 \\
\hline $\mathrm{N}-\mathrm{NH}_{4}$ & & 2.31 & 0.06 & 2.20 & 2.40 \\
\hline $\mathrm{N}-\mathrm{NO}_{2}$ & & 0.16 & 0.02 & 0.13 & 0.20 \\
\hline $\mathrm{N}-\mathrm{NO}_{3}$ & & 1.67 & 0.07 & 1.54 & 1.81 \\
\hline
\end{tabular}

Statistical analyses were carried out using the Statistica 13.3 software in the Polish language version.

\section{RESULTS AND DISCUSSION}

In the conducted studies the uptake of dissolved oxygen present in the model wastewater and the transformation of carbon and nitrogen compounds were observed (Table 3 ). The average dissolved oxygen concentration in the model influents was above $6 \mathrm{mg} \cdot \mathrm{L}^{-1}$, which made it possible to observe the transformation of carbon and nitrogen compounds under aerobic conditions. However, it should be emphasised that the type of conditions that prevailed in the biological bed depended mainly on the technological parameters of the filter bed. The relationship between the efficiency of particular parameters removal of wastewater flowing into the bed and the contact time of the treated medium with the biological layer of the bed became highly apparent. It should be emphasised that the removal efficiency of individual parameters in model wastewater increased with increasing contact time of the wastewater with the biological layer. In addition, a prolonged contact time promoted an increase in dissolved oxygen uptake rate (OUR). Throughout the experiment, changes in OUR were observed ranging from approximately $18 \%$ to over $96 \%$. COD removal efficiency varied from 13.38 to $62.15 \%$. Ammonium nitrogen was removed during the experiment with efficiencies ranging from 4.34 to $82.86 \%$, while $\mathrm{N}-\mathrm{NO}_{3}$ was removed with efficiencies ranging from 9.70 to $63.37 \%$. For $\mathrm{N}_{-} \mathrm{NO}_{2}$, removal effects were observed for the three longest contact times (385, 77 and 38 minutes). For retention times of 385 and 77 minutes, the removal efficiency of $\mathrm{N}-\mathrm{NO}_{2}$ was more than $95 \%$, while for a retention time of 38 minutes the removal effect of $\mathrm{N}^{-\mathrm{NO}_{2}}$ was $0.50 \%$. For retention times shorter than 38 minutes only higher concentrations of this nitrogen form were observed in the effluent flowing out of the bed compared to the influent flowing in, resulting in negative values of the $\mathrm{N}-\mathrm{NO}_{2}$ removal effect.

Biodegradation of carbon compounds expressed as COD (Fig. 1) was most intense at the lowest flow velocities. The increase in COD concentration in effluents flowing out of the bed was characterised by a trend of change close to logarithmic. The lowest COD concentration in the outflow was observed in the range of linear flow velocity from 0.02 to $0.16 \mathrm{~m} \cdot \mathrm{h}^{-1}$. At velocities ranging from 0.23 to $0.60 \mathrm{~m} \cdot \mathrm{h}^{-1}$, COD in the filtration bed effluent varied from about $80.0 \mathrm{~m} \cdot \mathrm{h}^{-1}$ to over $100.0 \mathrm{~m} \cdot \mathrm{h}^{-1}$. It should be stressed that a clear increase in COD in the filtration bed effluent was observed between filtration velocities of 0.16 and $0.23 \mathrm{~m} \cdot \mathrm{h}^{-1}$. The gradual increase in COD concentration in the effluent flowing from the bed may be a result of the decreasing contact time of the effluent with the biological layer [Yang et al. 2009, Pedrosa et al. 2019]. Hence, the amount of microorganisms that were present in the unit volume of the filter bed did not show the ability to decompose the increasing amount of nutrients at a higher filtration velocity [de Silva and de Campos 2021]. In addition, the relatively lower COD 
Table 3. Carbon and nitrogen removal efficiency and oxygen uptake rate in the filter bed during the experiment

\begin{tabular}{|c|c|c|c|c|c|c|}
\hline $\begin{array}{c}\mathrm{V}_{\mathrm{F}} \\
{\left[\mathrm{m} \cdot \mathrm{h}^{-1}\right]}\end{array}$ & $\begin{array}{c}\mathrm{T}_{\mathrm{B}} \\
{[\mathrm{min}]}\end{array}$ & $\begin{array}{c}\text { OUR } \\
{\left[\mathrm{mg} \cdot \mathrm{L}^{-1}\right]}\end{array}$ & $\begin{array}{c}\mathrm{COD} \\
{\left[\mathrm{mg} \cdot \mathrm{L}^{-1}\right]}\end{array}$ & $\begin{array}{c}\mathrm{N}-\mathrm{NH}_{4} \\
{\left[\mathrm{mg} \cdot \mathrm{L}^{-1}\right]}\end{array}$ & $\begin{array}{c}\mathrm{N}-\mathrm{NO}_{2} \\
{\left[\mathrm{mg} \cdot \mathrm{L}^{-1}\right]}\end{array}$ & $\begin{array}{c}\mathrm{N}-\mathrm{NO}_{3} \\
{\left[\mathrm{mg}^{-1} \mathrm{~L}^{-1}\right]}\end{array}$ \\
\hline 0.02 & 385 & $96.78 \pm 1.14$ & $62.15 \pm 2.07$ & $82.86 \pm 0.53$ & $93.33 \pm 0.01$ & $61.73 \pm 0.01$ \\
\hline 0.08 & 77 & $91.82 \pm 0.39$ & $50.43 \pm 2.92$ & $69.12 \pm 0.94$ & $93.75 \pm 0.01$ & $63.37 \pm 0.01$ \\
\hline 0.16 & 38 & $80.42 \pm 1.01$ & $46.88 \pm 3.26$ & $52.83 \pm 2.65$ & $0.50 \pm 0.01$ & $51.79 \pm 0.01$ \\
\hline 0.23 & 26 & $75.79 \pm 1.19$ & $24.07 \pm 4.67$ & $24.97 \pm 4.17$ & $-85.71 \pm 0.01$ & $31.71 \pm 0.01$ \\
\hline 0.32 & 19 & $73.94 \pm 1.24$ & $19.62 \pm 4.44$ & $14.19 \pm 6.14$ & $-63.16 \pm 0.01$ & $24.55 \pm 0.01$ \\
\hline 0.40 & 15 & $69.04 \pm 1.80$ & $16.70 \pm 4.55$ & $8.51 \pm 7.58$ & $-153.33 \pm 0.01$ & $22.48 \pm 0.01$ \\
\hline 0.46 & 13 & $44.53 \pm 2.86$ & $14.43 \pm 3.50$ & $10.03 \pm 2.81$ & $-164.29 \pm 0.01$ & $17.26 \pm 0.01$ \\
\hline 0.55 & 11 & $21.15 \pm 4.63$ & $12.52 \pm 3.97$ & $12.87 \pm 6.89$ & $-100.00 \pm 0.01$ & $9.70 \pm 0.01$ \\
\hline 0.60 & 10 & $17.91 \pm 4.38$ & $13.38 \pm 4.07$ & $4.34 \pm 4.78$ & $-77.78 \pm 0.01$ & $11.98 \pm 0.01$ \\
\hline
\end{tabular}

values observed at the three lowest linear flow velocities may result from the fact that both anaerobic and aerobic conditions for the decomposition of carbon compounds occurred in the filter bed $[\mathrm{Xi}$ et al. 2005]. This type of phenomenon is reflected in the concentration of dissolved oxygen in the effluent flowing from the bed, which at velocities between 0.02 and $0.16 \mathrm{~m} \cdot \mathrm{h}^{-1}$ was no higher than $1.58 \mathrm{mg} \cdot \mathrm{L}^{-1}$. On the other hand, at filtration velocities above $0.23 \mathrm{~m} \cdot \mathrm{h}^{-1}$ aerobic conditions predominated in the filter bed, as indicated by higher dissolved oxygen concentrations in the effluent flowing out of the bed. Thus, the described observations indicate that the velocity of wastewater flow through the bed is of key importance in the biodegradation of carbon compounds expressed as COD. As the linear flow velocity primarily determines the contact time of the wastewater with the biological layer and consequently determines the uptake rate of dissolved oxygen and nutrients present in the wastewater [El Mouhri et al. 2019, Chaouki et al. 2020].

Due to the fact that the dissolved oxygen concentration in the effluent flowing into the bed was $6.16 \mathrm{mg} \cdot \mathrm{L}^{-1}$ on average, the changes in $\mathrm{N}-\mathrm{NH}_{4}$ concentration (Fig. 2) at each of the filtration velocities were dictated by the occurrence of the nitrification process. Similarly to the changes observed in the case of COD, the concentration of $\mathrm{N}_{-} \mathrm{NH}_{4}$ in the outflow from the filter bed increased with increasing flow velocity through the bed. This phenomenon results from a gradual decrease in the contact time with the biological part of the filter, which consequently also led to a lower oxygen uptake rate [Gonzalez-Martinez et al. 2007, Adam et al. 2019]. This resulted in a decrease in the intensity of the nitrification process and, consequently, in higher concentrations of $\mathrm{N}-\mathrm{NH}_{4}$ in the outflow from the filter bed.

It should be emphasised here that the nitrification process takes place in two stages. The first of these leads to the oxidation of ammonium ions to nitrate (III) and is referred to as nitritation. In turn, the second stage of nitrification, referred to as nitratation, leads to the oxidation of nitrate (III) to nitrate (V), as the more stable form in the aquatic environment. However, it should be emphasised that the oxygen consumption in

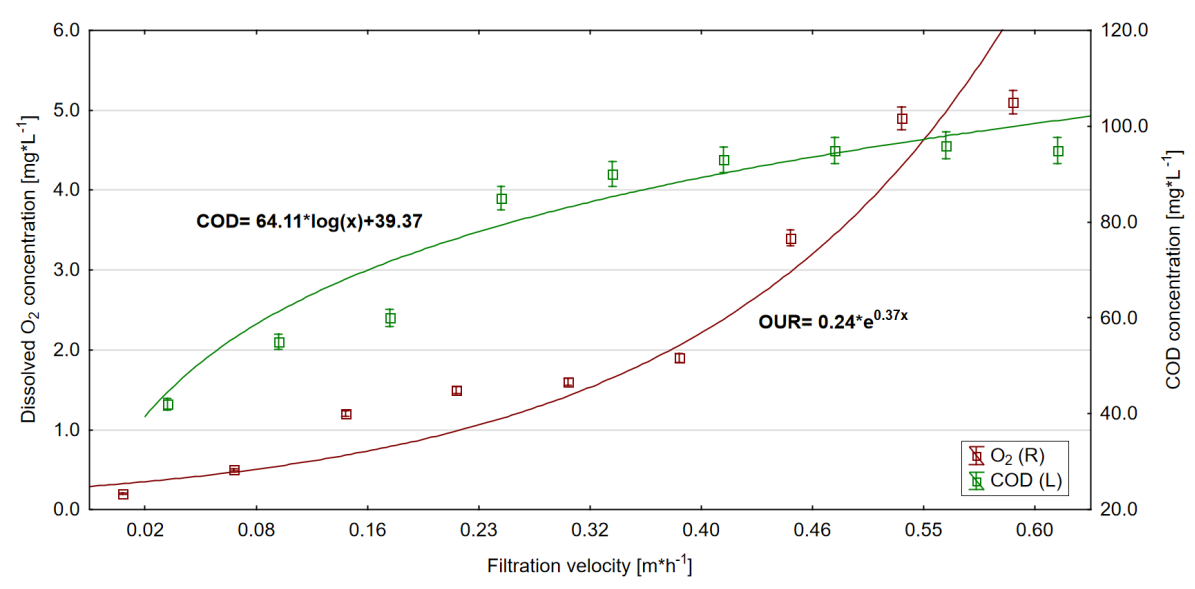

Figure 1. COD biodegradation during the experiment 


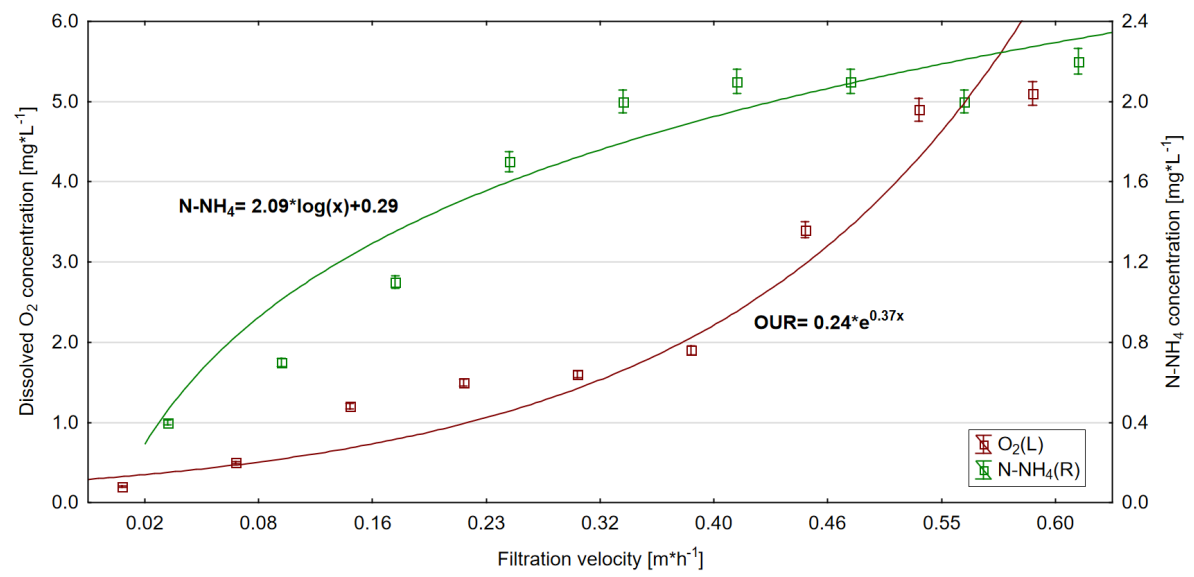

Figure 2. Transformation of $\mathrm{N}-\mathrm{NH}_{4}$ during the experiment

the two nitrification steps is different and that nitritation requires $2.67 \mathrm{mg} \mathrm{O}_{2}$ for the oxidation of $1 \mathrm{mg} \mathrm{NH}_{4}^{+}$to $\mathrm{NO}_{2}^{-}$. In contrast, the nitratation process requires $0.34 \mathrm{mg} \mathrm{O}$ for the oxidation of $1 \mathrm{mg} \mathrm{NO}_{2}^{-}$to $\mathrm{NO}_{3}^{-}$[Shan et al. 2014, Guven et al. 2016]. Hence, under conditions of limited availability of dissolved oxygen in the treated medium, nitritation is the dominant process (Fig. 3). The described phenomenon was observed in the

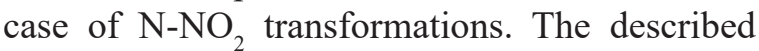
character of the first stage of nitrification was particularly evident at filtration velocities above $0.23 \mathrm{~m} \cdot \mathrm{h}^{-1}$, where higher $\mathrm{N}-\mathrm{NO}_{2}$ concentrations were observed in the effluent flowing out of the bed compared to the effluent flowing into the bed. On the other hand, at filtration velocities between 0.02 and 0.16 , lower $\mathrm{N}-\mathrm{NO}_{2}$ concentrations were observed compared to the wastewater entering the bed. This observation indicates that at lower filtration velocities, both the contact time and the amount of oxygen in the treated effluent were sufficient for nitrification to occur.
The previously mentioned nitration process and its exact course is difficult to interpret due to the fact that $\mathrm{NO}_{3}{ }^{-}$ions were present in the raw wastewater flowing into the bed. Nevertheless, the transformation of $\mathrm{N}^{-\mathrm{NO}_{3}}$ (Fig. 4) allowed to determine the intensity with which the denitrification process proceeded. It should be emphasised that a reduction of $\mathrm{N}-\mathrm{NO}_{3}$ was observed at each of considered filtration velocities. However, the denitrification process was most intense at filtration velocities between 0.02 and $0.16 \mathrm{~m} \cdot \mathrm{h}^{-1}$. This observation may be related to the longer residence time of the wastewater in the filter bed and the resulting better uptake of dissolved oxygen present in the wastewater flowing into the bed [Farabegoli et al. 2003].

The analysis of Pearson correlation coefficients showed that the transformation of carbon compounds expressed as COD and individual studied nitrogen forms depended most significantly on the technological parameters of the filtration bed. Both the wastewater flow and

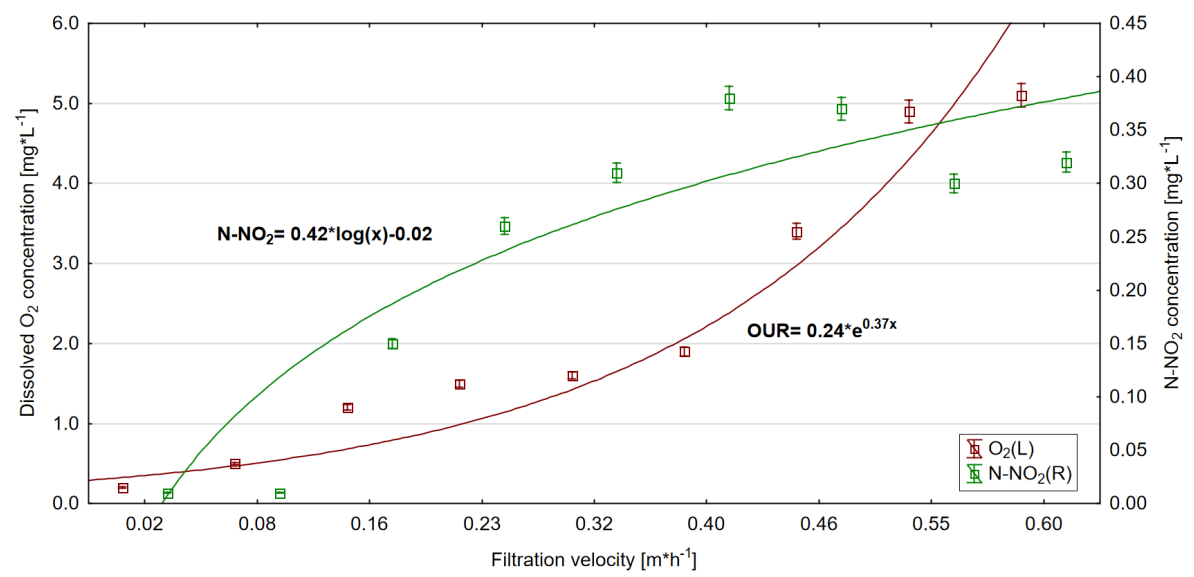

Figure 3. Transformation of $\mathrm{N}-\mathrm{NO}_{2}$ during the experiment 


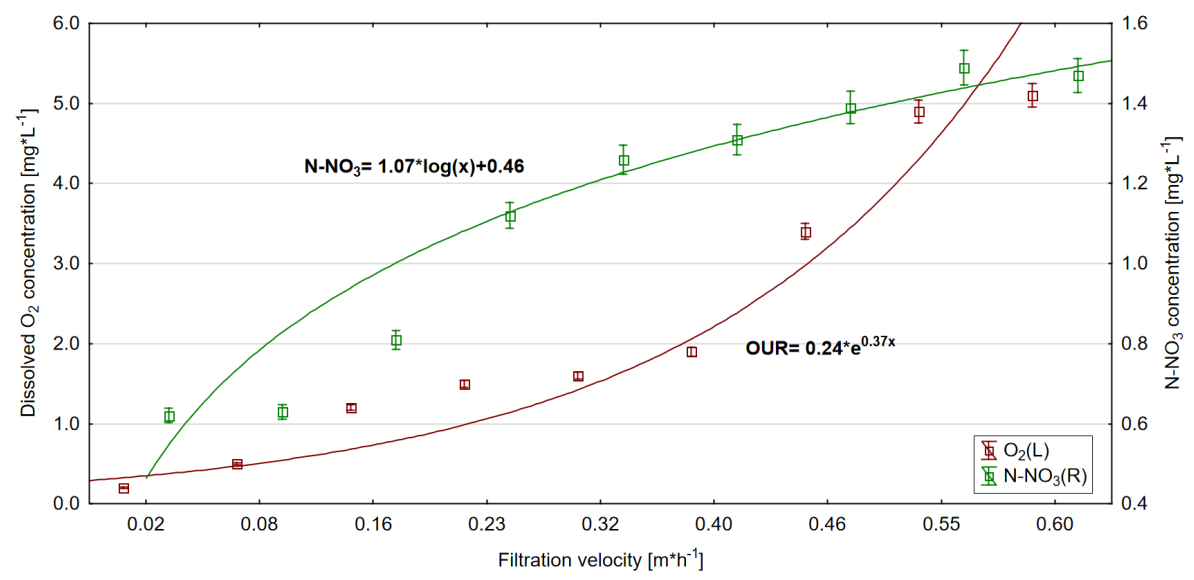

Figure 4. Transformation of $\mathrm{N}-\mathrm{NO}_{3}$ during the experiment

Table 4. Pearson correlation coefficients between wastewater parameters and technological parameters of the filtration bed

\begin{tabular}{|l|c|c|c|c|c|}
\hline \multicolumn{1}{|c|}{ Variable } & $\mathrm{TWW}-\mathrm{O}_{2}$ & $\mathrm{TWW}-\mathrm{COD}$ & $\mathrm{TWW}-\mathrm{N}-\mathrm{NH}_{4}$ & $\mathrm{TWW}-\mathrm{N}^{-\mathrm{NO}_{2}}$ & $\mathrm{TWW}^{2} \mathrm{~N}-\mathrm{NO}_{3}$ \\
\hline $\mathrm{Q}$ & 0.95 & 0.89 & 0.90 & 0.84 & 0.95 \\
\hline $\mathrm{T}_{\mathrm{B}}$ & -0.53 & -0.77 & -0.77 & -0.71 & -0.66 \\
\hline $\mathrm{HLR}$ & 0.95 & 0.89 & 0.90 & 0.84 & 0.95 \\
\hline $\mathrm{RWW}-\mathrm{O}_{2}$ & 0.33 & 0.08 & 0.07 & 0.04 & 0.19 \\
\hline $\mathrm{RWW}-\mathrm{COD}$ & -0.35 & -0.15 & -0.12 & -0.05 & -0.21 \\
\hline $\mathrm{RWW}-\mathrm{N}-\mathrm{NH}_{4}$ & -0.01 & -0.05 & -0.01 & 0.03 & 0.00 \\
\hline $\mathrm{RWW}-\mathrm{N}_{4} \mathrm{NO}_{2}$ & 0.16 & 0.21 & 0.23 & 0.11 & 0.21 \\
\hline $\mathrm{RWW}-\mathrm{N}-\mathrm{NO}_{3}$ & 0.03 & 0.18 & 0.13 & 0.08 & 0.11 \\
\hline
\end{tabular}

Note: RWW- wastewater inflowing to filtration bed, TWW- treated wastewater

the hydraulic loading of the biological layer were positively correlated with all the considered parameters. This indicates that as the flow and filtration velocity increased, the values of the individual studied parameters in the treated wastewater increased. On the other hand, negative values of the Person's correlation coefficient were observed between the contact time of wastewater and the biological layer of the filtration bed, which indicates that with increasing contact time of wastewater with the biological layer, the values of individual studied parameters decreased. The described changes are directly reflected in the results of the conducted studies. It should be emphasised that no statistically significant correlation was observed between the values of the parameters in the wastewater flowing into the deposit and those in the wastewater flowing out of the deposit. This observation indicates that under the adopted experimental conditions the transformation of carbon and nitrogen compounds did not depend on the quality of wastewater flowing into the filtration bed, but the conditions of the process were of crucial importance.

\section{CONCLUSIONS}

The conducted research has shown that transformations of carbon and nitrogen compounds take place in the biological vertical filter under both aerobic and anaerobic conditions. The removal efficiency of the studied pollutants depended on the filtration velocity, and with an increase of this parameter a decrease was observed. In the case of dissolved oxygen, a reverse pattern to that described was observed, indicating that dissolved oxygen uptake rate is higher at lower filtration velocities. This studies have shown that anaerobic and aerobic conditions occur in the filter bed at filtration velocities from 0.02 to $0.16 \mathrm{~m} \cdot \mathrm{h}^{-1}$. Above this filtration velocity range, aerobic conditions dominate in the filtration bed.

\section{REFERENCES}

1. Adam M.R., Othman M.H.D., Abu Samah R., Puteh M.H., Ismail A.F., Mustafa A., Rahman M.A., Jaafar J. 2019. Current trends and future prospects of ammonia removal in wastewater: A comprehensive 
review on adsorptive membrane development. Separation and Purification Technology, 213, 114-132.

2. Andreottola G., Foladori P., Ziglio G. 2009. Biological treatment of winery wastewater: an overview. Water Science and Technology, 60(5), 1117-1125.

3. Chaouki Z., Zaitan H., Nawdali M., Vasarevicius S., Mazeikiene A. 2020. Oil removal from refinery wastewater through adsorption on low cost natural biosorbents. Environmental Engineering and Management Journal, 19(1), 105-112.

4. da Silva C.P., de Campos S.X. 2021. The effects of anaerobic reactor post-treatments by rapid filtration systems and conventional techniques. Environmental Science and Pollution Research (article in press).

5. Dong Y., Yuan H., Zhang R., Zhu N. 2019. Removal of ammonia nitrogen from wastewater: a review. Transactions of the Asabe, 62(6), 1767-1778.

6. El Mouhri G., Merzouki M., Miyah Y., El Karrach K., Mejbar F., Elmountassir R., Lahrichi A. 2019. Valorization of two biological materials in the treatment of tannery effluents by filtration Treatment of tannery effluents by filtration. Moroccan Journal of Chemistry, 7(1), 183-193.

7. Farabegoli G., Gavasci R., Lombardi F., Romani F. 2003. Denitrification in tertiary filtration: Application of an up-flow filter. Journal of Environmental Science and Health Part A-Toxic/Hazardous Substances \& Environmental Engineering, 38(10), 2169-2177.

8. Gizgis N., Georgiou M., Diamadopoulos E. 2006. Sequential anaerobic/aerobic biological treatment of olive mill wastewater and municipal wastewater. Journal of Chemical Technology \& Biotechnology, 81(9), 1563-1569.

9. Gonzalez-Martinez S., Millan T., Gonzalez-Barcelo O. 2007. Biological aerated filtration of municipal wastewater using a low-cost filtration media. Water Science and Technology, 55(7), 255-262.

10. Hassan S.M., Muhaimeed A.R., Abedalhammed H.S., Madlul N.S., Aun T.T. 2021. Potential applications of biological filtration media in changing water properties and subsequent effects on common carp (Cyprinus carpio) in recirculating aquaculture systems. Aquaculture Research, 52(1), 345-355.

11. Joshiba G.J., Kumar P.S., Femina C.C., Jayashree E., Racchana R., Sivanesan S. 2019. Critical review on biological treatment strategies of dairy wastewater. Desalination and Water Treatment, 160, 94-109.

12. Kanaujiya D.K., Paul T., Sinharoy A., Pakshirajan K. 2019. Biological Treatment Processes for the Removal of Organic Micropollutants from Wastewater: a Review. Current Pollution Reports, 5(3), 112-128.

13. Liang W., Hu H.Y., Song Y.D., Wang H., Guo Y.F., Che Y.L. 2007. Micronutrient niacin addition to enhance biological treatment of textile wastewater. Fresenius Environmental Bulletin, 16(4), 393-396.

14. Ma X.Y.Y., Dong K., Tang L., Wang Y.K., Wang X.C.C., Ngo H.H., Chen R., Wang N. 2020. Investigation and assessment of micropollutants and associated biological effects in wastewater treatment processes. Journal of Environmental Sciences, 94, 119-127.

15. Nasir N., Daud Z., Abd Kadir A., Latiff A.A., Ahmad B., Suhani N., Awang H., Oyekanmi A.A., Halim A.A. 2019. Removal of ammonia nitrogen from rubber industry wastewater using zeolite as adsorbent. Malaysian Journal of Fundamental and Applied Sciences, 15(6), 862-866.

16. Ofman P., Struk-Sokolowska J. 2019. Artificial Neural Network (ANN) Approach to Modelling of Selected Nitrogen Forms Removal from Oily Wastewater in Anaerobic and Aerobic GSBR Process Phases. Water, 11(8), article no. 1594.

17. Pedrosa A.L., Pedroza M.M., Cavallini G.S. 2019. Post-treatment of paint industry effluents by filtration using Andropogon biochar (Andropogon gayanus Kunth cv. Planaltina). Environmental Science and Pollution Research, 26(32), 33294-33303.

18. Rahimi S., Modin O., Mijakovic I. 2020. Technologies for biological removal and recovery of nitrogen from wastewater. Biotechnology Advances, 43, article no. 107570.

19. Shan M.J., Zhang Y., Kou L.H. 2014. Nitrogen balance and transformation in the nitrification process of coking wastewater and the influence on nitrification kinetics. Water Science and Technology, 69(7), 1541-1545.

20. Skorbilowicz M., Ofman P. 2014. Seasonal changes of nitrogen and phosphorus concentration in Suprasl River. Journal of Ecological Engineering, 15(1), 26-31.

21. Song Y.T., Du C.A., Wang H., Li X.M., Guo S.X. 2014. The Application of Biological Wastewater Treatment Technology in Shengli Oilfield. Petroleum Science and Technology, 32(18), 2239-2244.

22. Struk-Sokolowska J., Gwozdziej-Mazur J., Jadwiszczak P., Butarewicz A., Ofman P., Wdowikowski M., Kazmierczak B. 2020. The Quality of Stored Rainwater for Washing Purposes. Water, 12(1), article no. 252.

23. Turkmenler H., Aslan M. 2017. An evaluation of operation and maintenance costs of wastewater treatment plants: Gebze wastewater treatment plant sample. Desalination and Water Treatment, 76, 382-388.

24. Veetil D.P., Arriagada E.C., Mulligan C.N., Bhat S. 2021. Filtration for improving surface water quality of a eutrophic lake. Journal of Environmental Management, 279, article no. 111766. 
25. Wang X.J., Chen S.L., Gu X.Y., Xiao J. 2008. Biological aerated filter treated washing wastewater for reuse using ozonation as a pre-treatment, in Wang X., Chen R. Advances in Chemical Technologies for Water and Wastewater Treatment, 517-523.

26. Wang Z.J. 2020. Advanced Treatment Process for Secondary Effluent of Municipal Wastewater Based on A/O Biological Filtration Technology, International Symposium on Energy Environment and Green Development, 657, article no. 012002.

27. Xi J., Mancl K.M., Tuovinen O.H. 2005. Carbon transformation during sand filtration of cheese processing wastewater. Applied Engineering in Agriculture, 21(2), 271-274.

28. Yang K., He J.J., Dougherty M., Yang X.J., Li L. 2009. Municipal wastewater treatment through an aerobic biofilm SBR integrated with a submerged filtration bed. Water Science and Technology, 59(5), 917-926.

29. Yang Z.H., Dong J.X., Liu L., Shuang Y., Wan B.J., Liu D.S. 2021. Algae slurry pressured filtration by biological aerated filter: a laboratory scale study. Fresenius Environmental Bulletin, 30(6A), 6827-6832. 